\title{
The Location of Conduction Abnormalities in Human Entrapment Neuropathies
}

\author{
WILLIAM F. BROWN, GARY G. FERGUSON, MICHAEL W. JONES AND STEPHEN K. YATES
}

\begin{abstract}
SUMMARY: Direct stimulation of 23 median, 13 ulnar and 2 peroneal nerves at the time of surgical exploration has been used to locate, and characterize the conduction abnormalities in the nerves. The most frequent location of the major conduction abnormalities in the median nerve was in the first $1-2 \mathrm{~cm}$ distal to the origin of the carpal tunnel. In the ulnar nerve the important conduction abnormalities were located most frequently in the segments $1 \mathrm{~cm}$ proximal and distal to the medial epicondyle. In the peroneal nerve the major conduction abnormalities occurred proximal or distal to the entry point of the common peroneal nerve into the peroneus longus muscle.
\end{abstract}

RÉSUMÉ: Une stimulation directe de 23 nerfs médians, 13 cubitaux et 2 péronés alt moment d'exploration chirurgicale a été utilisée pour localiser et caractériser les anomalies de conduction dans les nerfs. La localisation la plus fréquente des anomalies de conduction majeures dans le nerf médian est juste à côté de la limite proximale du retinaculum flexor, tout près de l'épicondyle médian dans le cas du nerf cubital, à proximité de la fibula dans un nerf péroné, mais distal à la tête fibulaire dans les autres nerfs péronés.

From the Department of Clinical Neurological Sciences, University Hospital, London, Ontario, Canada.

Reprint requests to: Dr. W. F. Brown, Dept. of Clinical Neurological Sciences, University Hospital, 339 Windermere Road, London, Ontario, Canada N6A 5A5.

\section{INTRODUCTION}

In man the localization of conduction abnormalities in ulnar and peroneal nerve entrapments has been limited by measurement of the mean conduction times and changes in muscle and nerve compound action potential over a 10 or more centimeter $(\mathrm{cm})$ length of the nerve bridging the level of 'entrapment' (Payan, 1969; Eisen, 1974; Singh et al., 1974). Similarly, methods to locate the conduction abnormalities in carpal tunnel, median nerve entrapments have been limited to measurement of the median motor terminal latency and the distal latencies of median digital sensory nerve action potentials (Simpson, 1956; Thomas, 1960; Thomas et al., 1967; Buchthal et al., 1974) and at times the transcarpal tunnel sensory conduction time (Wiederholt, 1970; Buchthal, Rosenfalck, 1971).

Histological investigation of the type and location of structural abnormalities in human peripheral nerve entrapments have also been limited (Marie, Foix, 1913; Sunderland, Bradley, 1952; Thomas, Fullerton, 1963; Chang et al., 1963; Neary, Eames, 1975; Neary et al., 1975). Recent reports of experimental acute pressure neuropathy and the chronic entrapment neuropathy in the guinea pig (Ochoa et al., 1972; Ochoa, Marotte, 1973) have stressed the probable importance of mechanical factors.

To understand the mechanisms of entrapment neuropathies in man it is important to locate and identify the types of conduction abnormalities in the disordered peripheral nerves. The method chosen to investigate these problems has been to stimulate the exposed nerves at multiple points and record the changes in the evoked maximum muscle compound potentials (MCPs) of muscles distal to the entrapment.

\section{METHODS}

\section{Patients:}

The clinical data of patients with median and ulnar nerve entrapments is listed in Table I and II respectively. Fifteen percent of the patients with median nerve entrapment had thenar (T) wasting and $85 \%$ of the patients with ulnar nerve entrapment had hypothenar (HT) wasting. The common peroneal nerve neuropathies located at the fibular head were the result of direct compression. Each patient was examined clinically and investigated electrophysiologically pre and post operatively.

\section{Surgical Exposure:}

The intraoperative investigations were carried out under general anesthesia except for a 78-year-old man with median neuropathy. 'The pneumatic tourniquet, if used in the period of surgical exposure of the nerve, was released at least $15 \mathrm{mi}$ nutes prior to the electrophysiological investigations. In no case was the tourniquet used longer than $25 \mathrm{mi}$ nutes. No neuromuscular blocking agents were used. The temperature of the exposed nerves could not be properly controlled in the operating room. The temperature on the surface of the 5 exposed nerves in which it was recorded varied from 28 to $35^{\circ} \mathrm{C}$

The ulnar nerves were exposed and freed from surrounding tissues $4-5 \mathrm{~cm}$ proximal $(-)$ and distal $(+)$ to the medial epicondyle tip; a length that included $1-2 \mathrm{~cm}$ proximal and distal to the cubital tunnel entrance. (Figure 1). 


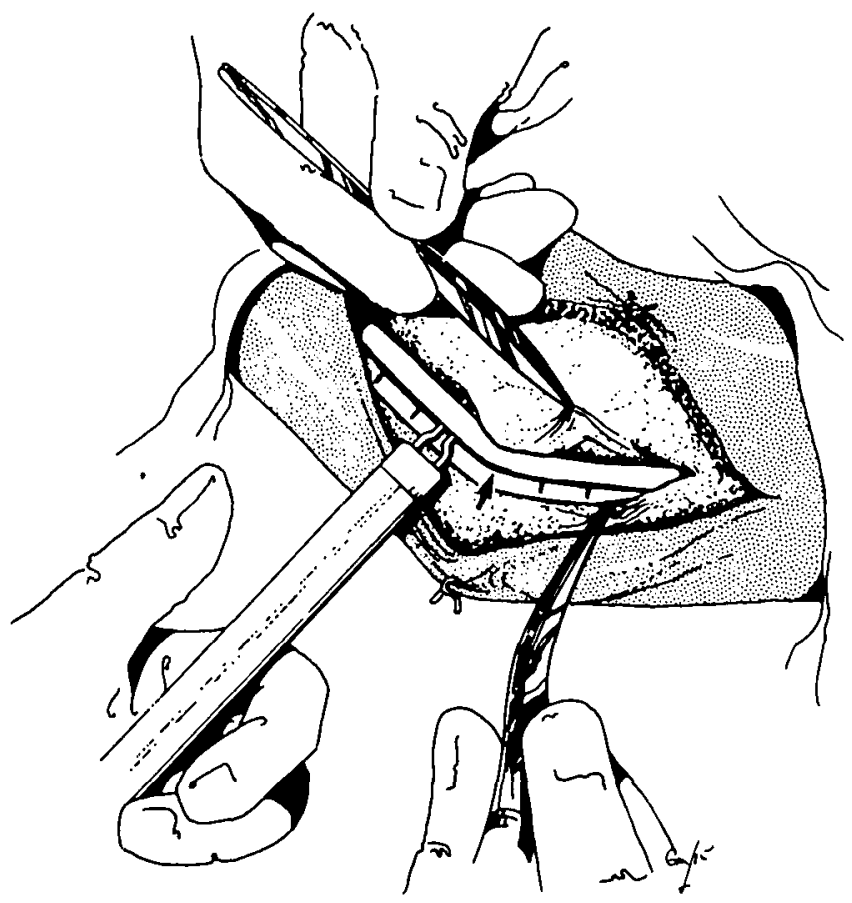

Figure 1-Method of stimulation of the exposed ulnar nerve. The arrow points to the tip of the medial epicondyle. On the right, forceps mark the proximal edges of the divided aponeurosis of the flexor carpi ulnaris. Stimulation by means of bipolar electrodes, the cathode being placed at successive 1 centimeter marks.

The surgical exposure of the median nerve permitted stimulation of the nerve at least $1-2 \mathrm{~cm}$ proximal $(-)$ to the origin of the flexor retinaculum and, in most, distal ( + ) as far as the origin of the recurrent thenar motor branch.

The common peroneal nerve divides into 2 major divisions, superficial and deep, distal to the entry point of the nerve into the peroneus longus muscle. The common peroneal was stimulated proximal to the peroneus longus muscle bridge and the deep peroneal division distal to this point. Thus, it was possible to compare the maximum compound potentials of the extensor digitorum brevis (EDB) evoked by stimulation proximal ( $($ ) and distal $(+)$ to the fibular head.

Paper measuring tapes that did not change in length when wet, were trimmed to fit the length of the nerve. The surface tension held the tapes firmly enough to avoid movement.

\section{Electrophysiology:}

The parameters measured (Fig. 2) included the peak to peak voltage
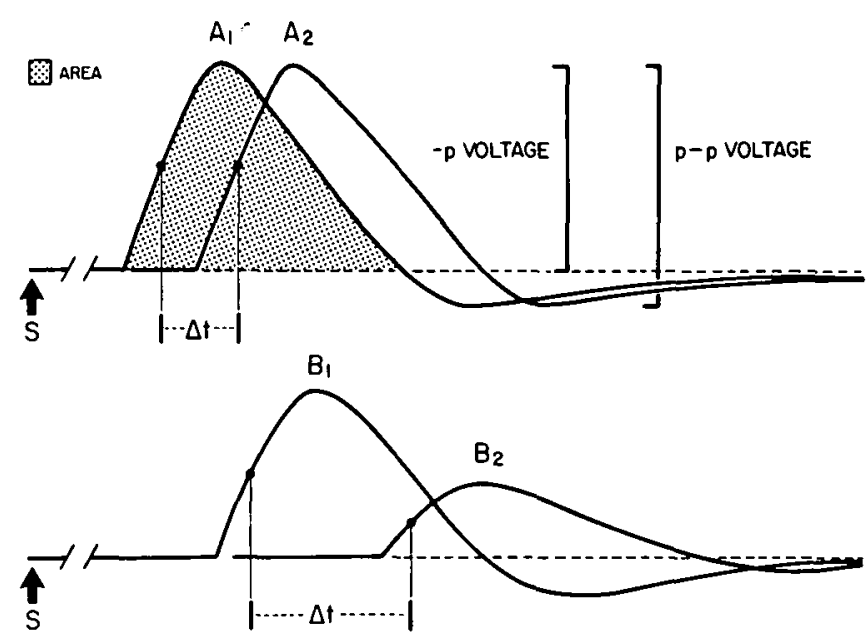

Figure 2-Illustration of the parameters of the maximum compound potentials (MCP) measured:

Peak to peak voltage (p-pV)

Negative peak voltage $(-p \mathrm{p})$

Negative potential area

UPPER: Muscle maximum compound potentials ( $A_{1}$ and $A_{2}$ ) evoked by stimulation at two points along the length of a nerve. In healthy nerve, little (less than 5\%) change in the negative potential area or $p$-p voltage occurs between stimulation points less than $20 \mathrm{~cm}$ apart. Only the negative potential area was measured because late $(\mathrm{F}$ or $\mathrm{H})$ discharges can contribute to the positive potential. $S$ denotes stimulus.

LOWER: A significant reduction in the voltage and negative potential area of the muscle maximum compound potential (MCP) (B2) evoked by stimulation at a point proximal to a nerve entrapment point compared to the $M C P\left(B_{1}\right)$ evoked by distal stimulation is illustrated.

The one half negative peak latency change; here designated $(\Delta t)$ was chosen as the conduction time index because it was difficult at times to identify the precise point of origin of the initial negative inflexion from the baseline of individual motor units and compound motor potentials. Note, however, that changes in the rise time of the initial negative inflexion could lead to disproportionally greater changes in the conduction time than would otherwise be obvious from measurements of the conduction time between initial negative inflexions.

(p-pV), negative peak voltage $(-\mathrm{pV})$, the $1 / 2-\mathrm{pV}$ latency and the negative potential area. The last was included to partially correct for changes in the $-p V$ and $p-p V$ that could have resulted from changes in the impulse velocities of motor units contributing to the maximum compound potential. Except for complex potentials that necessitated measurement of the conduction times by hand, all the parameters were measured by means of a program utilizing a Hewlett-Packard 2100 S computer. The area measurements in the earliest investigations were obtained by means of a Hewlett-Packard 9864A digitizer.
The maximum compound potentials of thenar (T), hypothenar (HT), extensor digitorum brevis (EDB) and in one case peroneus brevis were recorded by means of surface electrodes using conventional methods (Brown, Feasby, 1974). For comparison to the maximum compound (HT) and (EDB) potentials produced by stimulation of the exposed nerve, the respective (HT) and (EDB) maximum compound potentials evoked by percutaneous stimulation of the ulnar nerve at the level of the wrist and anterior tibial nerve at the level of the ankle, were recorded at the time of the intraoperative investigations. In the me- 
dian nerve, carpal tunnel entrapments, it was most important to locate the earth electrode properly to limit the occasional, troublesome, stimulus artifact produced by stimulation of the median nerve at the distal end of the tunnel. An uninsulated needle electrode inserted into the thenar mass between the stimulating and recording electrodes was used as the earth electrode. Changes in the stimulus artifact from stimulation point to stimulation point along the length of the nerve sometimes necessitated changes in the location of the earth electrode to best minimize the artifact.
To locate and identify the type of conduction abnormality, the exposed nerves were stimulated directly by means of bipolar DISA 13 K72 electrodes. The interelectrode distance was $6 \mathrm{~mm}$ and the diameter of each of the electrodes $1 \mathrm{~mm}$. The tips of this electrode were bent into semicircular hooks onto which the nerve was lifted, free from the nearby tissues. The ulnar and peroneal nerves were stimulated at $1.0 \mathrm{~cm}$ intervals and the median nerve at $0.5 \mathrm{~cm}$ intervals by means of isolated pulses, 0.05-0.1 milliseconds in duration, and frequency less than 1 per second delivered by a

TABLE I

CARPAL TUNNEL 'ENTRAPMENTS'

TOTAL NUMBER PATIENTS $=20$

AGE DISTRIBUTION:

\begin{tabular}{cc} 
Age & No. of Patients \\
\cline { 2 - 2 } $0-20$ yrs. & 0 \\
$20-30$ yrs. & 1 \\
$30-40$ yrs. & 5 \\
$40-50$ yrs. & 6 \\
$50-60$ yrs. & 4 \\
$60-70$ yrs. & 2 \\
$70-80$ yrs. & 2
\end{tabular}

ASSOCIATED DISORDERS:

Diabetes mellitus

Rheumatoid arthritis

CARPAL TUNNEL INVOLVEMENT:

Clinically bilateral

unilateral

Female 15

Male 5

Intraoperative investigations bilateral

Total median nerves

intraoperatively investigated

Thenar wasting

Absent

Mild-Moderate

Severe

MOTOR TERMINAL LATENCY (MTL):

Patients $<60$ years of age

Patients 60 and over

Controls $<60$ years of age
2

1

12

8

3

23

20

2

1

$5.2 \pm 1.7$ msec. $\quad \mathrm{N}=19$ Range $\quad(3.9-11.0 \mathrm{msec}$. $)$

$8.4 \pm 3.9$ msec. $\quad \mathrm{N}=4$

Range $\quad(5.5-14.0 \mathrm{msec}$.

$3.8 \pm 0.5 \mathrm{msec} . \quad \mathrm{N}=55$

$(3.0-4.9 \mathrm{msec}$.)
Devices 3072 isolated stimulator. Particular care was taken to increase the stimulus voltage to a level just supramaximal to evoke a maximum counpound potential in order to limit extension of the stimulus current beyond the stimulation point.

Except for the early intraoperative investigations photographed directly at the time, all later investigations have been recorded on an FM Phillips tape recorder. Trains of 10 or more stimulus pulses at each point were recorded and later analyzed in the manner outlined.

Note was made in each case of changes in the circumference, color and location of external abnormalities of the exposed nerve.

\section{RESULTS \\ I. MEDIAN NERVE ENTRAPMENTS - CARPAL TUNNEL}

1. Operative Findings:

All 23 median nerves were constricted along the length of the carpal tunnel. In only 7 was the constriction confined to a length less than 2 $\mathrm{cm}$. Such focal constrictions were most commonly located in the first 1 to $2 \mathrm{~cm}$ distal to the proximal border of the flexor retinaculum. In 3 median nerves explored, the nearby synovial tissue was thickened. Bluish discoloration was noted in 2 median nerves. It was difficult to judge the importance of thickening of the flexor retinaculum. This observation has been reported in most of the explored median nerves but has not been checked against the findings in age matched control subjects. In cadaver hands, thickening of the flexor retinaculum in the mid segment has been reported (Robbins, 1963).

\section{Conduction Block:}

In 6 median nerves the negative potential area of the ( $\mathrm{T}$ ) maximum compound potential increased more than $10 \%$ as the point of stimulation moved from proximal to distal along the nerve (Fig. 3A). The 'unblock' occurred distal to the $0.5 \mathrm{~cm}$ segment having the maximum conduction time in 2 median nerves and over the identical segment in 4 median nerves. In the remaining $17 \mathrm{me}$ - 

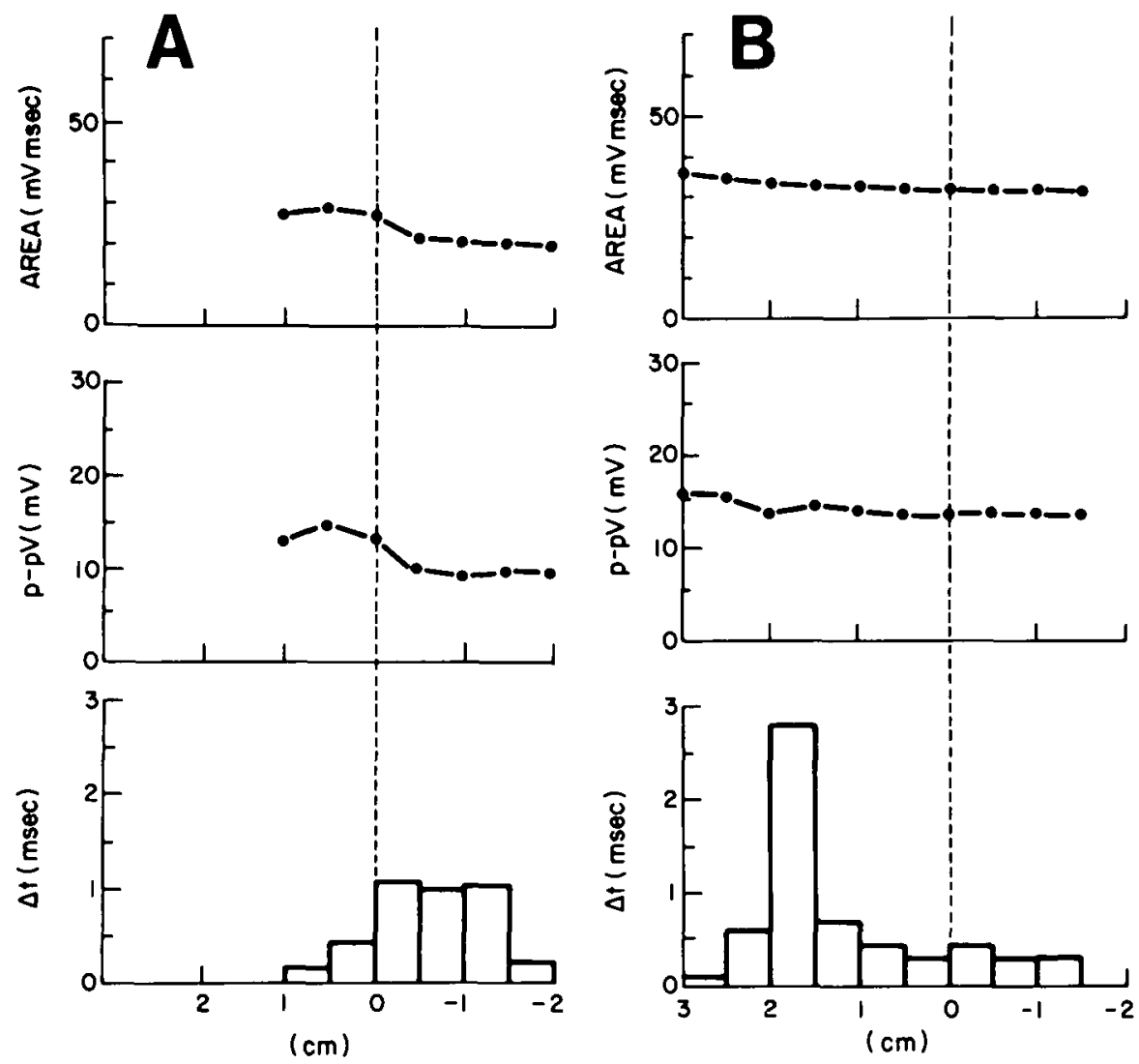

Figure 3A-Female, 38-years-old, who had clinical evidence suggesting the carpal tunnel syndrome. The motor terminal latency (MTL) measured preoperatively was $5.3 \mathrm{msec}$.

At operation the median nerve was observed to be flattened along the length of the carpal tunnel but no enlargement was noted proximal to the carpal tunnel. The most abnormal increases in conduction time $(\Delta t)$ occurred proximal to the origin of the carpal tunnel. Significant conduction block, evident from the change in the negative potential area and the negative potential voltage was observed.

$3 B$-Female, 63 years of age with typical carpal tunnel sensory symptoms. The preoperative motor terminal latency (MTL) was $8.1 \mathrm{msec}$. Local constriction of the median nerve was noted between 1.5 and $2.0 \mathrm{~cm}$ distal to the origin of the carpal tunnel; the maximum increase in conduction time occurring in the identical segment.

Zero (0) marks the origin of the carpal tunnel; stimulation points proximal to the tunnel being denoted by the negative (-) sign. The plots of the conduction time $(\Delta \mathrm{t})$ in milliseconds ( $\mathrm{msec}$ ), peak to peak voltage in millivolts $(\mathrm{mV})$ and negative potential area in millivolt milliseconds $(\mathrm{mVmsec})$ of the maximum thenar compound potentials evoked by stimulation of the median nerves at points proximal (-) and distal to the origin of the carpal tunnel are illustrated.

dian nerves no significant change in the negative potential area or $p-p$ voltage of the (T) maximum compound potential was observed.

\section{Location of Conduction Time} Abnormalities:

The location of the $0.5 \mathrm{~cm}$ segment(s) having the maximum conduction time(s) was proximal $(-)$ to the flexor retinaculum in 4 median nerves, one example of which is shown in Fig. 3A. It was also found in the first 1 to $2 \mathrm{~cm}$ distal to the proximal border of the flexor retinaculum in 15 median nerves (Figs. 3B, \& 4) and distal to $2 \mathrm{~cm}$ in 4 median nerves (Fig. 4). A focal in- crease in the conduction time (a conduction time over a $0.5 \mathrm{~cm}$ segment of a nerve more than 2 times the conduction time of the other 0.5 $\mathrm{cm}$ segments) was noted in $6 \mathrm{me}$ dian nerves. An example of such a focal increase in conduction time is illustrated by Fig. 5. This diabetic, 54-year-old female had a median motor terminal latency of $4.7 \mathrm{msec}$ but no thenar wasting or weakness. The local constriction of the median nerve was observed between 0 and 2 $\mathrm{cm}$. Between 0 and $0.5 \mathrm{~cm}$ an increase in conduction time occurred $(1.2 \mathrm{msec})$ that corresponded to a conduction velocity of $4.0 \mathrm{~m} / \mathrm{s}$.

In the other 17 median nerves, the abnormal increase in the conduction time was more evenly distributed along the length of the nerves (Fig. 4). The maximum conduction times recorded over a single $0.5 \mathrm{~cm}$ segment in the 23 median nerves had a range of 0.3 to $5.9 \mathrm{msec}$, the latter representing a maximum conduction velocity less than $1 \mathrm{~m} / \mathrm{s}$. This abnormal conduction time occurred in a diabetic that had a preoperative thenar motor terminal latency of $11.0 \mathrm{msec}$, intraoperative evidence of conduction block and a bluish discoloration of the median nerve in the carpal tunnel. (Fig. 6)

\section{ULNAR NERVE ENTRAPMENTS}

\section{Operative Findings:}

The ulnar nerve was bound down by connective tissue in the epicondylar groove in 7 cases, enlarged in the epicondylar groove in 2 cases and edematous along its entire length in one case. Enlargement of the ulnar nerve in the epicondylar groove was not as frequent as reported in cadavers (Chan et al., 1963) or at operation (Richards, 1945; Jensen, 1959).

In no ulnar nerve was deformation or constriction of the nerve seen at the level of the aponeurotic arch of the flexor carpi ulnaris muscle. This is in contrast to the observations of Feindel and Stratford (1957). Focal constrictions of the ulnar nerve were noted in 2 cases, in one between 0 and $1 \mathrm{~cm}$ and in the other distal to the cubital tunnel from 2 to $3 \mathrm{~cm}$.

2. Motor Conduction Velocities: Conduction velocity measure- 


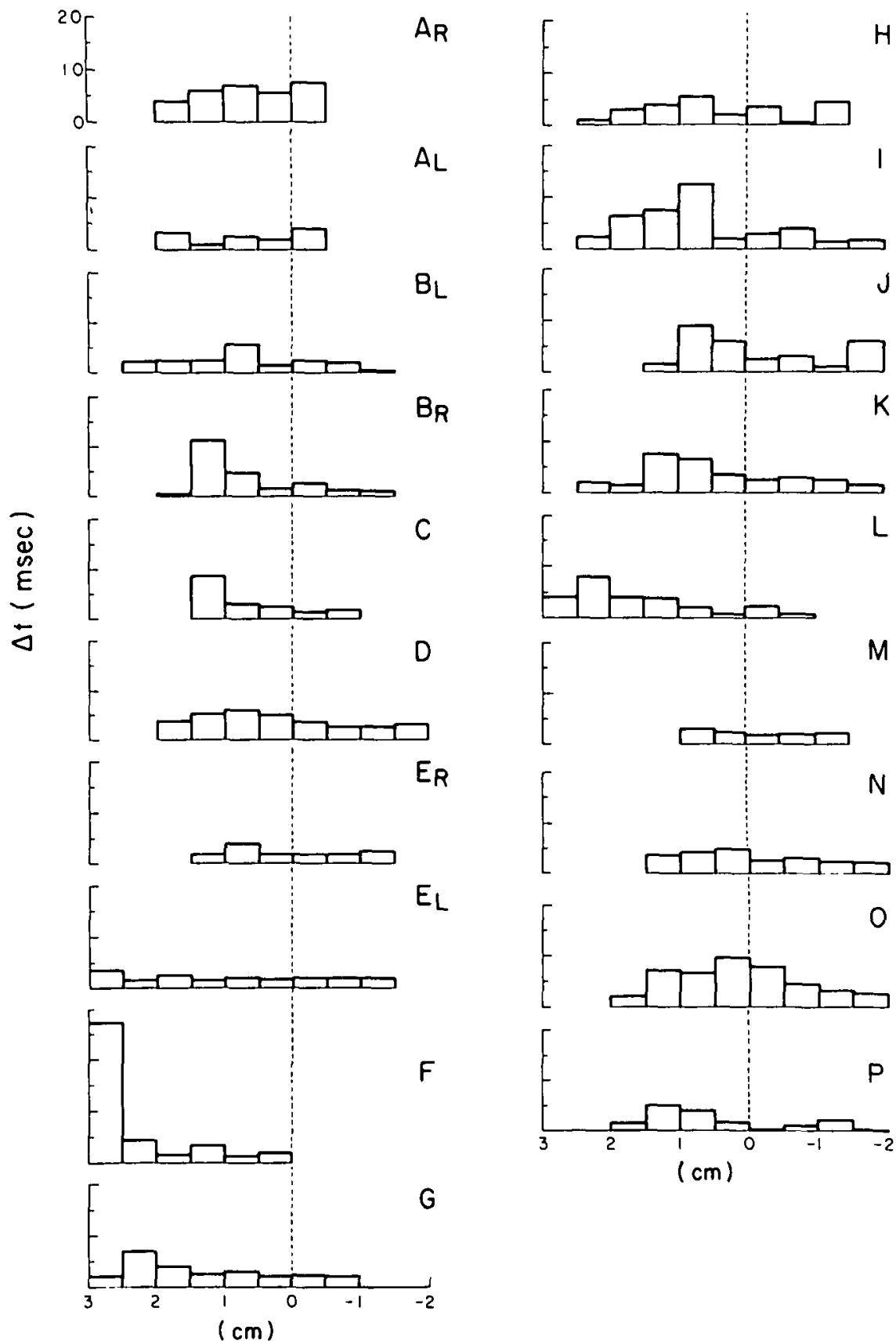

Figure 4-Plots of the conduction times $(\Delta t)$ in 17 median nerves investigated by intraoperative stimulation of the nerves are illustrated. The right $(R)$ and left $(L)$ hands of patients investigated bilaterally are illustrated. 0 marks the origin of the carpal tunnel.

ments in the ulnar nerves of the 14 patients investigated intraoperatively and controls are listed in Table III. The maximum motor conduction velocity in the ulnar nerves across the elbow segment was obtained by measurement of the distance between stimulation points proximal and distal to the sulcus with the elbow flexed as suggested by Checkles et al., (1971). In 2 cases with normal preoperative maximum motor conduction velocities over the elbow segment, significant but usually focal abnormalities of the conduction time in $1 \mathrm{~cm}$ segments were observed on intraoperative direct stimulation of the nerve (Fig. 7).

3. Conduction Block:

Conduction block was noted in 4 ulnar nerves. The block occurred distal to the segments(s) having the maximum conduction time(s) in 2 ulnar nerves. In one male alcoholic, who reported paresthesia in the ulnar digits and had minimal (HT) wasting, an increase in the (HT) $p-p$ voltage and negative potential area and the maximum increase in the conduction times occurred over
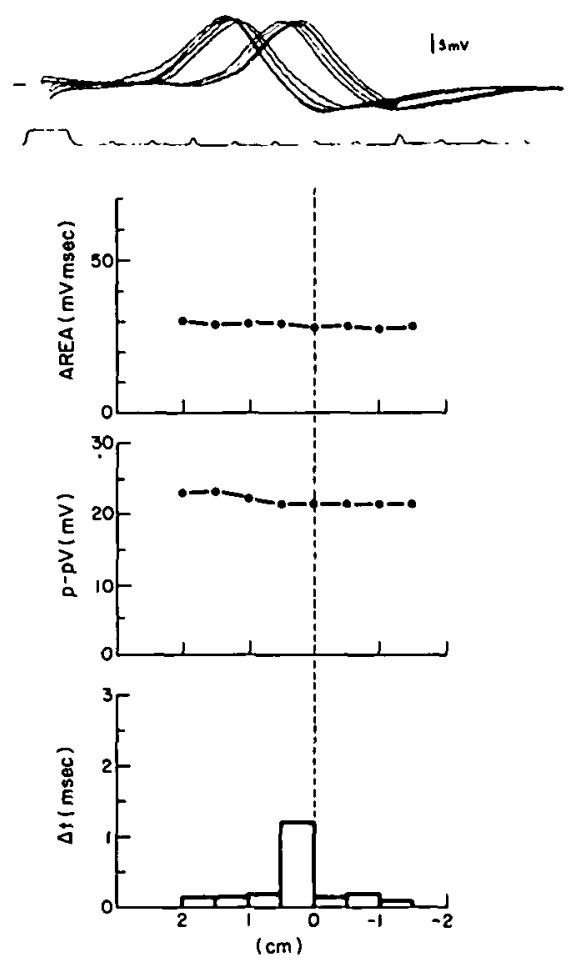

Figure 5-Female, diabetic, 54 years of age who had sensory symptoms characteristic of the carpal tunnel entrapment. The preoperative motor terminal latency was 4.7 milliseconds. Intraoperatively, a constriction of the median nerve was observed between 0 (the origin of the carpal tunnel) and 2 $\mathrm{cm}$ distal to the carpal tunnel origin. No conduction block was evident but an increase in the conduction time was observed between -0.5 to $0 \mathrm{~cm}$. UPPER: The maximum compound thenar potentials evoked by stimulation at points proximal and distal to the origin of the carpal tunnel are illustrated. The largest conduction time gap occurred over the $0.5 \mathrm{~cm}$ segment immediately proximal to the carpal tunnel border. No significant change in the voltage or negative potential area of the maximum compound potentials occurred. Time scale in milliseconds.

BELOW: The voltage and areas of the thenar maximum compound potentials together with the corresponding interval conduction times are plotted. Symbols as per Figure 3. 
TABLE II

ULNAR NERVE 'ENTRAPMENTS'

TOTAL NUMBER OF PATIENTS $=13 \quad$ Female 1

Male 12

AGE DISTRIBUTION:

$\begin{array}{cc}\text { Age } & \text { No. of Patients } \\ 0-30 \text { yrs. } & 0 \\ 30-40 \text { yrs. } & 1 \\ 40-50 \text { yrs. } & 6 \\ 50-60 \text { yrs. } & 3 \\ 60-70 \text { yrs. } & 3\end{array}$

ASSOCIATED DISORDERS:

Extensive alcohol intake

Diabetes mellitus

Post hospitalization ( > 3 weeks)

Post operative

Cervical spondylosis

Arthritis elbow

4

2

3 ( 1 alcoholic)

1

2

0

HYPOTHENAR WASTING:

$\begin{array}{ll}\text { Absent } & 2 \\ \text { Mild - Moderate } & 8 \\ \text { Severe } & 3\end{array}$

the $1 \mathrm{~cm}$ segments proximal and distal to the tip of the medial epicondyle. (Fig. 8)

Another patient with marked (HT) wasting had 19 distinct motor unit potential steps that could be counted by graded electrical stimulation of the ulnar nerve at the level of the wrist. At -4 to $-1 \mathrm{~cm}$ only 2 distinct motor unit potential steps could be counted. Stimulation at points 0 to 2 evoked 3 distinct motor unit potential steps and 2 additional motor unit potential steps could be excited at 3 and $4 \mathrm{~cm}$. These observations have been shown in Fig. 9 and point to conduction block in (HT) motor axons occurring over a long length of the nerve at the elbow. The maximum conduction block apparently occurred distal to $4 \mathrm{~cm}$ in the forearm.

\section{Conduction Time Abnormalities:}

In certain patients, the conduction time abnormality(ies) were restricted to a short $1-2 \mathrm{~cm}$ length of the nerve (Fig. 8). One example of such a restriction is illustrated in Fig. 10. This patient had paresthesia and numbness in the ulnar distribution, minimal (HT) wasting, but no evidence of denervation or hypothenar motor unit loss. The negative potential area and $p-p V$ of the hypothenar maximum compound potentials evoked by stimulation of the ulnar nerve at points proximal and distal to the medial epicondyle and at the level of the wrist did not differ much even though a minimal change in the configuration and $p-p$ voltage of the hypothenar maximum compound potential occurred across the tip of the medial epicondyle. The most marked abnormalities were the increases in conduction time over the $1 \mathrm{~cm}$ segments proximal and distal to the tip of the medial epicondyle.

Figure 11 shows the abnormal increases in conduction time more evenly distributed over the length of the ulnar nerve (Fig. 11). In this nerve, no significant change occurred in the negative potential area or $\mathrm{p}-\mathrm{pV}$ of the hypothenar maximum compound potentials evoked by stimulation at the level of the wrist compared to stimulation at points as much as $5 \mathrm{~cm}$ proximal and $5 \mathrm{~cm}$ distal to the tip of the medial epicondyle. The clinically and electrophysiologically least ulnar neuropathy included was a female aged 34 who reported intermittent tingling in the IVth and Vth digits only. Pre-operatively she had a normal hypothenar motor unit estimate ard a reduction in the maximum motor conduction velocity across the elbow segment to 46 meters. The motor conduction times by intraoperative stimulation of the nerve in the $1 \mathrm{~cm}$ proximal and distal to the medial epicondyle were approximately twice the conduction times over $1 \mathrm{~cm}$ segments that could be expected in control nerves based on surface stimulation $(0.15-0.20$ msec), but conduction block was not noted.

The distribution of conduction time abnormalities in 8 other ulnar nerves is illustrated in Fig. 12. The largest increases in conduction time were located proximal to the cubital tunnel and in all but 1 case were proximal to the medial epicondyle tip or between 0 to $1 \mathrm{~cm}$.

\section{PERONEAL NERVE NEUROPATHY}

In the first case, the common peroneal nerve was reported to be enlarged proximal to the entry of the nerve into the peroneus longus muscle. The negative potential area of the extensor digitorum brevis (EDB) maximum compound potential increased $40 \%$ from -2 to $0 \mathrm{~cm}$; the conduction times being correspondingly increased from -4 to $0 \mathrm{~cm}$.

In the second case (Fig. 13) an equally obvious increase in negative potential area and p-pV of the (EDB) and peroneus brevis maximum compound potentials occurred when the deep branch of the peroneal nerve was stimulated distal ( + ) to reference point 0 (the entry point in the peroneus longus muscle). The maximum increase in the conduction times corresponded to the segments of the nerve in which the conduction block was observed. In this nerve, a dense fibrous tissue band was noted about the nerve at the point of entry into the peroneus longus muscle. From inspection of the nerve at surgery no explanation was obvious for the abnormal conduction times in (EDB) and peroneus brevis axons in the nerve from -3 to $-2 \mathrm{~cm}$.

\section{DISCUSSION}

The motor terminal latency and digital sensory potential distal latencies represent conduction times in a nerve more than $5.0 \mathrm{~cm}$ in length in the median nerve. In the ulnar and 

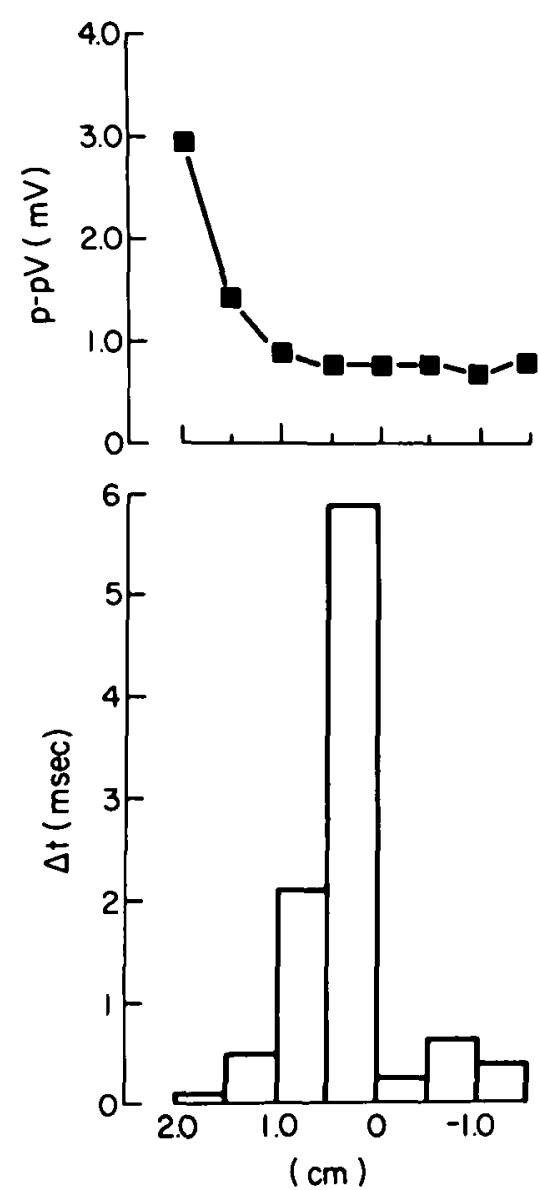

Figure 6-Diabetic male, 49 years of age, who complained of pain and numbness in the fingers of both hands. The preoperative motor terminal latency was $11.0 \mathrm{mil}$ liseconds. Intraoperatively, the median nerve was observed to be markedly contricted along the length of the carpal tunnel.

RIGHT: The maximum thenar compound potentials evoked by stimulation of the exposed median nerve at $0.5 \mathrm{~cm}$ intervals, proximal (-) and distal to the origin of the carpal tunnel are illustrated. Stimulation at each point was just supramaximal for the observed evoked potential. Changes in the stimulus artifact are partly the result of changes in the distance between stimulating and recording electrodes and the angle subtended by the nerve and long axis of the thenar muscles. The position of the earth electrode had to be changed between -1.0 and $-1.5 \mathrm{~cm}$ and again between 0 and $0.5 \mathrm{~cm}$ in order to minimize the stimulus artifact. That the second potential inflexion recorded at $1.0 \mathrm{~cm}$ is not the same potential inflexion noted between 0 and $-1.5 \mathrm{~cm}$ is evident by the differences in potential configuration and area and the longer latency of the second potential compared to the potential latency at $0 \mathrm{~cm}$.

LEFT: The changes in conduction time $(\Delta t)$ and voltage $(p-p V)$ of the evoked potentials are plotted, 0 corresponding to the origin of the carpal tunnel. In this case, the conduction times $(\Delta t)$ were calculated to the initial inflexion of the thenar compound potential and not the one-half negative potential amplitude. The maximum conduction time occurred between 0.0 and $0.5 \mathrm{~cm}$. Major conduction blocks occurred between 0 and 0.5 and $1.0 \mathrm{~cm}$ and again between 1.5 and $2.0 \mathrm{~cm}$.

Symbols are as in Figure 3.

peroneal nerves the minimum disidnce between electrodes located distal and proximal to the entrapment has been at least $10 \mathrm{~cm}$ (Payan, 1969; Eisen, 1974; Singh et al., 1974). As a consequence, even marked focal abnormalities in conduction time could lead to little significant overall change in the maximum conduction velocity in the nerves.

The most frequent locations of the important conduction abnormalities in the ulnar nerve were $1 \mathrm{~cm}$ proximal and distal to the medial epicondyle. In the median nerve they were in the first $1-2 \mathrm{~cm}$ distal to the beginning of the carpal tunnel. In the peroneal nerve, the most abnormal conduction times occurred proximal or distal to the entry of the common peroneal nerve into the peroneus longus muscle.

Variations in the location of the conduction abnormalities were common. In some median and ulnar nerves the abnormal conduction times and conduction block were evenly distributed along the length of the nerve. In other nerves the conduction abnormalities occurred in unusual positions. For example, in the median nerve the largest increases in conduction time occurred proximal to the flexor retinaculum in about $18 \%$ or at the distal end of the carpal tunnel in $13 \%$ of the nerves investigated.

Local conduction abnormalities or pathological changes in the appearance of the ulnar nerve at the entrance to the cubital tunnel were not observed in the 13 nerves investigated. The entrance to the cubital tunnel was at least $2 \mathrm{~cm}$ distal to the tip of the medial epicondyle in each case. Nevertheless, the conduction time abnormalities observed in the first $3-4 \mathrm{~cm}$ proximal to the entrance of the cubital tunnel could have been the result of cubital tunnel entrapment. This is supported by the report that conduction abnormalities in a peripheral nerve may extend up to $7 \mathrm{~cm}$ proximal to the level of experimental crush (Cragg, Thomas, 1961). Nonetheless, the most obvious abnormalities in the appearance of the 14 ulnar nerves were located in the epicondylar grove, an observation in agreement with other reports (Nicolle, Woolhouse, 1965; Staal, 1970; Chang et al., 1963; McGowan, 1950; Jensen, 1959) and did not support the contention that the cubital tunnel entrapment is a frequent cause of ulnar neuropathy (Feindel, Stratford, 1957; Wadsworth, Williams, 1973; Eisen, Danon, 1974). However, a recent report of the pathology of ulnar nerve compression in man (Neary, 


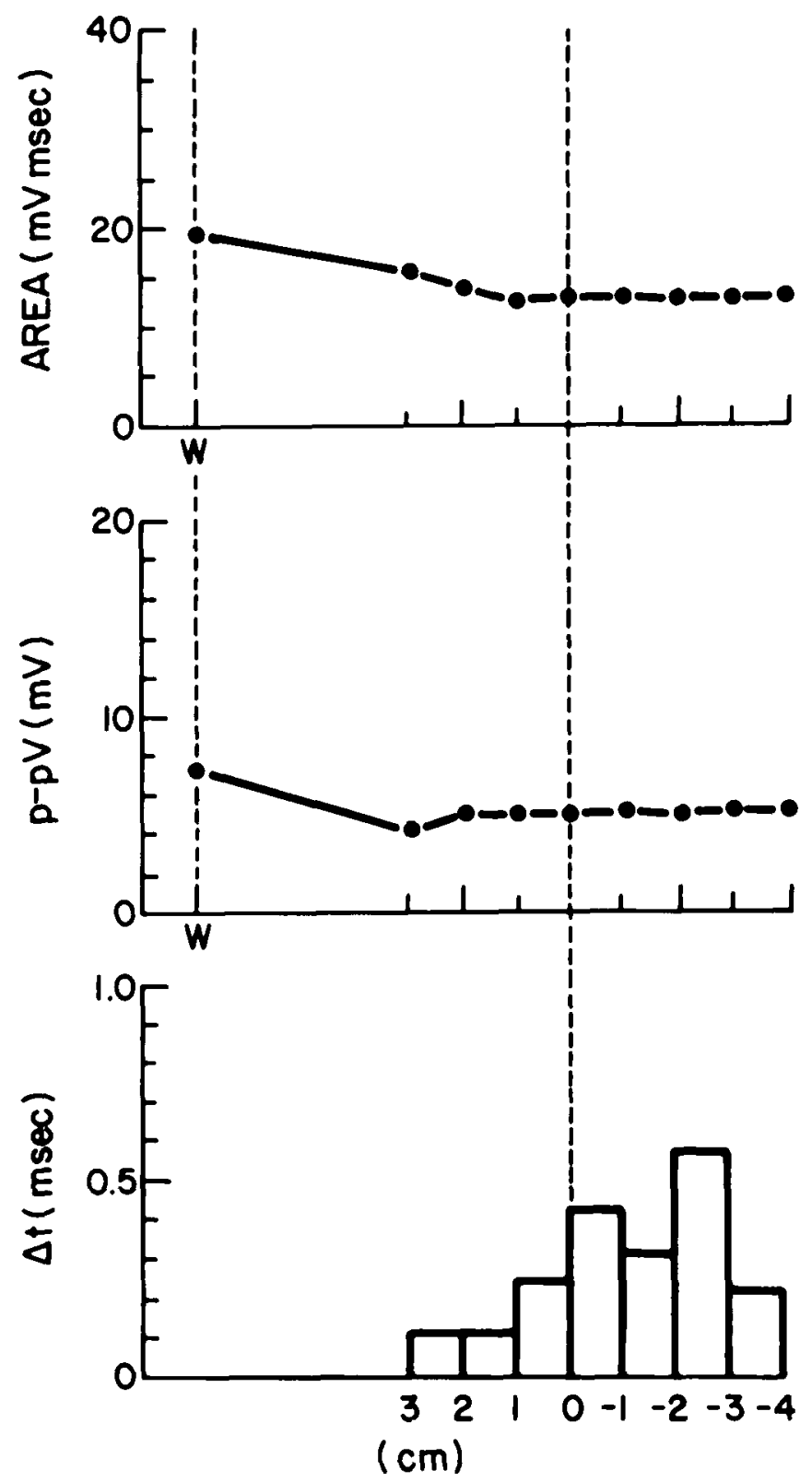

Figure 7-Retarded male epileptic on diphenylhydantoin and primidone with typical motor ulnar neuropathy including hypothenar muscle wasting. The maximum motor conduction velocity across the elbow was $\mathbf{5 6 . 8}$ metres per second, a value almost identical to the maximum velocities in the forearm and upper arm. Intraoperatively, increases in the conduction times were observed, particularly between $1 \mathrm{~cm}$ stimulation points proximal to the tip of the medial epicondyle.

Ordinate Symbols as per Figure 3. W denotes the point of stimulation at the wrist. Point 0 denotes the tip of the medial epicondyle and stimulation points proximal to the epicondyle tip are preceded by a negative (-) sign.
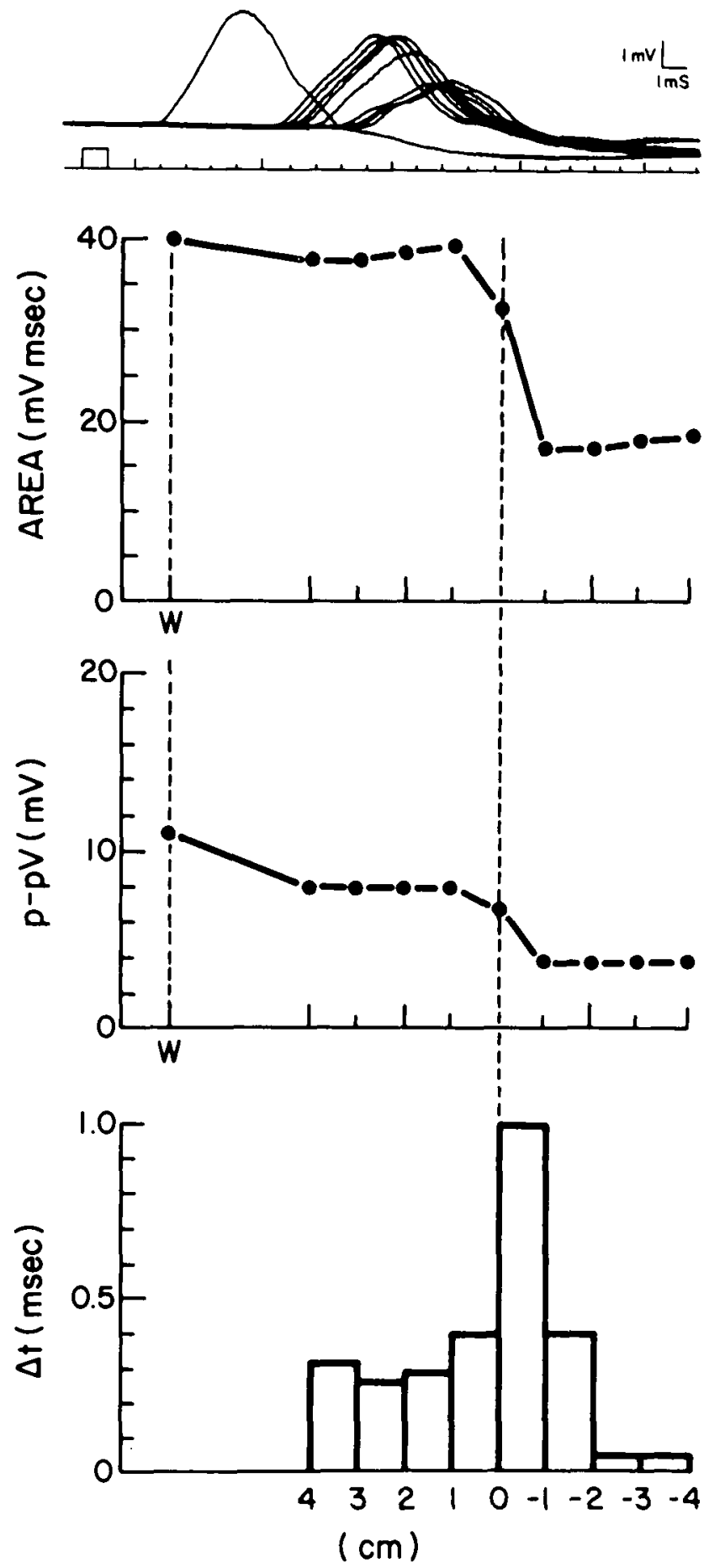

Figure 8-Male, 42, alcoholic with mild hypothenar muscle wasting.

UPPER: The maximum hypothenar compound potentials evoked by stimulation at points proximal and distal to the medial epicondyle and by stimulation at the level of the wrist are illustrated.

BELOW: The corresponding plots of the changes in the negative potential area, peak to peak voltage and conduction times are plotted. Symbols used are the same as in Figure 7.

Between $-1 \mathrm{~cm}$ and $1 \mathrm{~cm}$ the negative potential area increased by a factor of 2 . The maximum conduction time over a $1 \mathrm{~cm}$ segment was located between $-1.0 \mathrm{~cm}$ and $0 \mathrm{~cm}$ (tip of the medial epicondyle). 


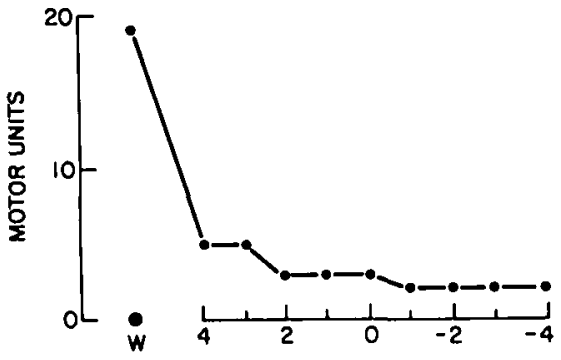

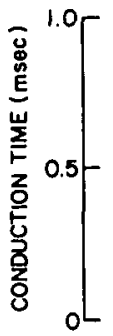

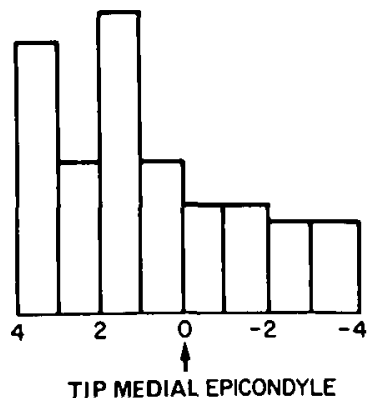

Figure 9-UPPER: Graph illustrating the number of distinct motor unit potential steps that could be evoked by graded stimulation of the ulnar nerve at the wrist $(W)$ and at points -4 to 4 along the exposed length of the ulnar nerve at the elbow.

LOWER: Changes in the conduction time between excessive maximum hypothenar compound potentials evoked by stimulation at successive 1 $\mathrm{cm}$ segments. The cubital tunnel entrance was located $2 \mathrm{~cm}$ distal to the medial epicondyle.

Eames, 1975) described a firm nodular swelling of the ulnar nerve immediately proximal to the entrance to the cubital tunnel. The most prominent histological abnormalities extended for a distance $1.5 \mathrm{~cm}$ proximal and distal to the entrance. The exact location of the injury to the ulnar nerve is likely to remain in doubt until more extensive histological and electrophysiological data on human ulnar neuropathies becomes available.

Conduction block was not frequent, occurring in $1 / 3$ of the ulnar nerves and only $1 / 4$ of the median nerves. Both peroneal nerves had conduction block. It might be expected that the conduction block would occur in the segments of the nerve having the maximum increase in conduction time. Exceptions were found in which the block occurred distal to the segments having the maximum increases in conduction
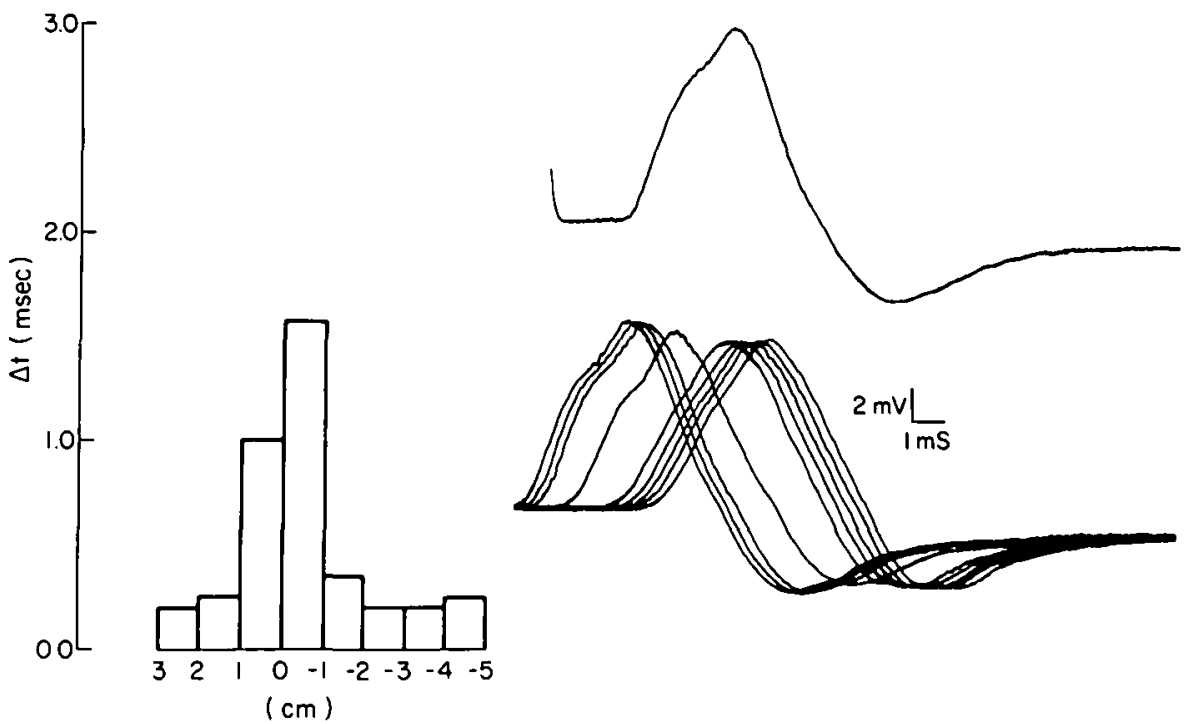

Figure 10-Male, 49 years of age, with clinical symptoms of an ulnar neuropathy. RIGHT: Upper - The maximum hypothenar compound potential evoked by stimulation of the ulnar nerve at the level of the wrist.

Lower - The corresponding hypothenar maximum compound potentials evoked by stimulation of the exposed ulnar nerve at $1 \mathrm{~cm}$ intervals proximal $(-)$ and distal to the tip of the medial epicondyle $(0)$. No significant change in the negative potential area occurred but minimal changes in the configuration of the maximum compound potentials occurred between $-1 \mathrm{~cm}$ and $1 \mathrm{~cm}$ that could represent changes in the relative conduction velocities of the component motor axons between -1 and 0 but not conduction block.

LEFT: The corresponding conduction times $(\Delta t)$ over successive $1 \mathrm{~cm}$ segments of the ulnar nerve are plotted.

Symbols are as in Figure 7.
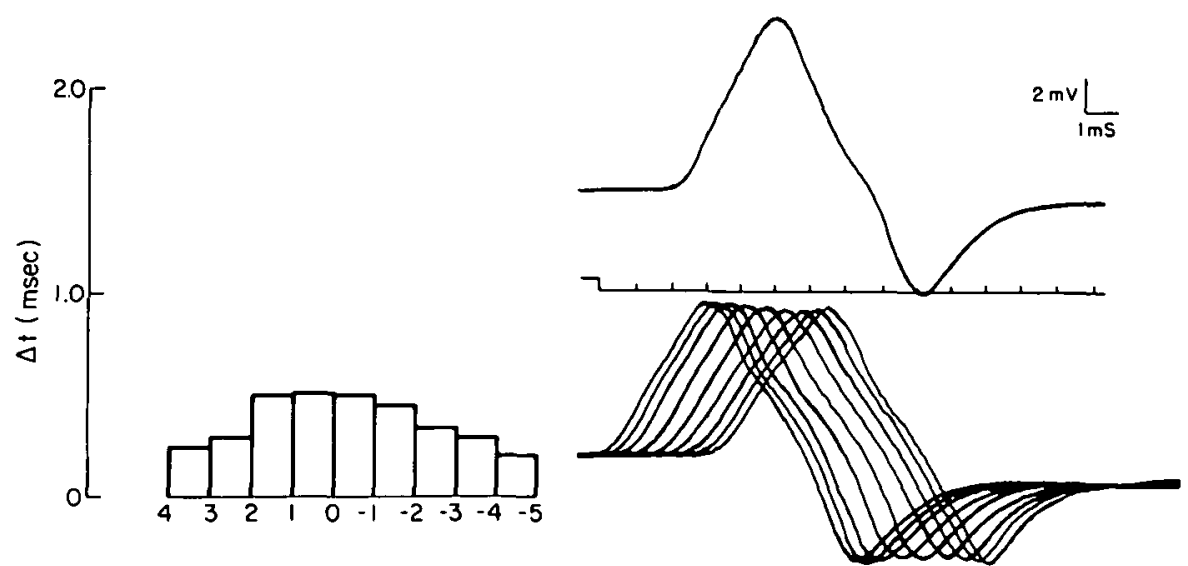

Figure $1 /$-Male, diabetic, 47 years of age with stocking sensory loss in the legs. Hypothenar muscle wasting was present.

RIGHT: The maximum hypothenar compound potential evoked by stimulation of the ulnar nerve at the wrist (upper) can be compared to the corresponding potentials evoked by nerve stimulation proximal and distal to the tip of the medial epicondyle (below)

LEFT: The corresponding conduction times $(\Delta t)$ over successive $1 \mathrm{~cm}$ segments proximal (-) and distal to the medial epicondyle are plotted. 


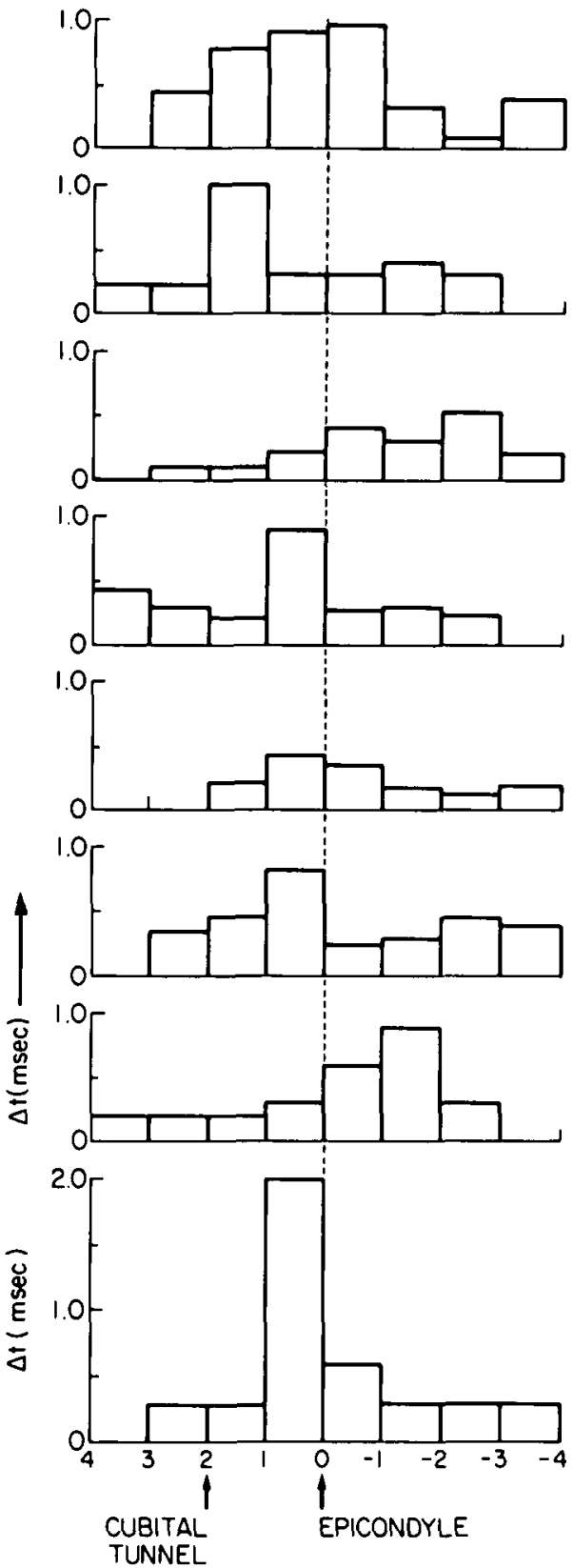

Figure 12-The conduction time plots in 8 ulnar nerves, not illustrated in other figures, none having evidence of conduction block. The location of the tip of the medial epicondyle and most proximal location of the cubital tunnel entrance are noted. Conduction times $(\Delta \mathrm{t})$ of successive $1.0 \mathrm{~cm}$ segments of the ulnar nerve in milliseconds are illustrated.

The conduction times of the patient with the clinically and electrophysiologically most mild ulnar neuropathy is the 5 th from the top.
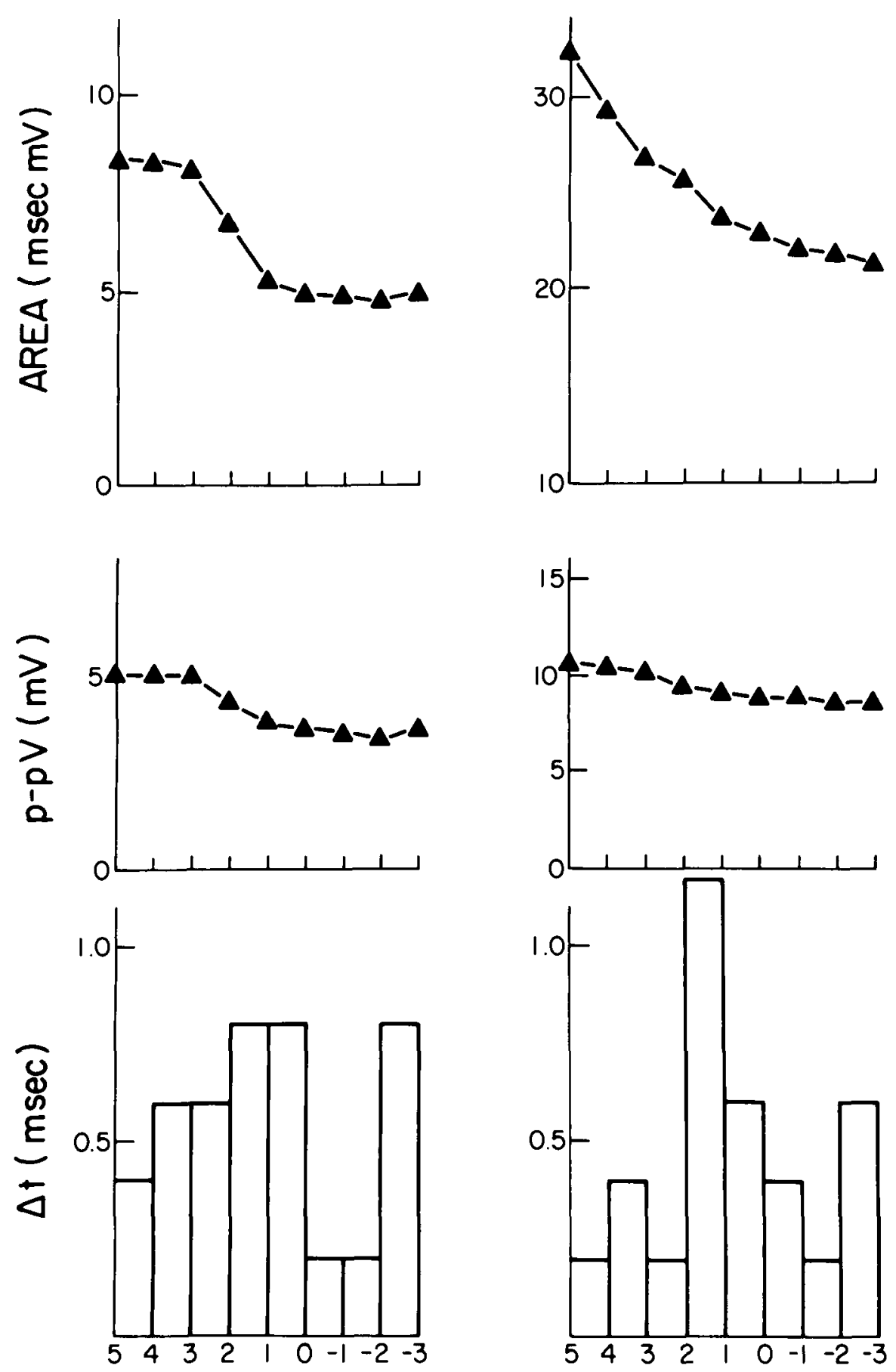

EDB

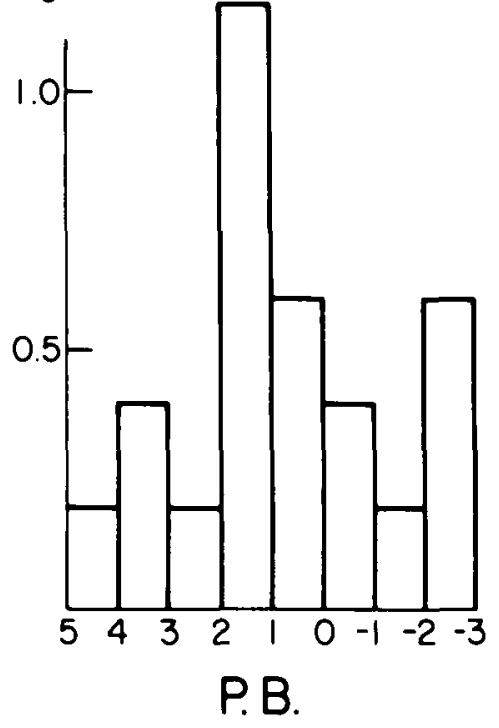

Figure 13-Male, 14 years of age with a peroneal neuropathy of 4 weeks duration. 0 , represents the point of entry of the peroneal nerve into the peroneus longus muscle. Points proximal to that entry point are preceded by the sign (-). The maximum compound potentials recorded on the surface from the peroneus brevis (PB) and extensor digitorum brevis (EDB) muscles were recorded and the corresponding parameters plotted for each of the stimulation points proximal and distal to the point 0 . The conduction times $(\Delta t)$ between successive maximum extensor digitorum brevis and peroneus brevis compound potentials evoked by stimulation at $1 \mathrm{~cm}$ intervals are plotted together with the corresponding changes in peak to peak voltage (p-pV) and negative potential areas $(\mathrm{mV} \mathrm{msec})$. 
TABLE III

MAXIMUM MOTOR CONDUCTION VELOCITY

(metres per second)

$\begin{array}{ccc}\mathrm{FA}^{*} & \mathrm{E}^{* *} & \mathrm{UA} \\ & & \\ 47.1 \pm 10 & 38.5 \pm 12.6 & 61.8 \pm 16.2 \\ 41-60 & 20-66.7 & 48-72 \\ & & \\ 60.2 \pm 2.6 & 59.6 \pm 10.6 & 62.6 \pm 8.5 \\ 58-64 & 47-85 & 50-79\end{array}$

ULNAR NEUROPATHIES $N=13$

Range

$58-64$

$47-85$

tural abnormalities in human nerve entrapments and electrophysiological information including stimulation of the nerves over shorter segments, measuring the changes in conduction of sensory impulses over the same segments and control of the nerve temperature would all be useful. It would also be of interest to relate the outcome of surgical treatment of the nerve entrapments to the type and location of conduction abnormalities in the nerves.

\section{ACKNOWLEDGMENTS}

We wish to thank Mr. Bruce Grayson for technical assistance and Drs. L. Hurst, S. Brash and $C$. Drake for the opportunities to carry out the intraoperative investigations.

nerve. For that reason, the exact point of excitation of the nerve fibers may not be directly opposite the cathode despite the care taken to insure that the stimulating voltage was just supramaximal for the maximum compound potential.

In patients with no clinical evidence of a disorder of the peripheral nerves clearcut structural abnormalities have been observed in the median nerve at the level of entrapment in the carpal tunnel and in the ulnar groove, particularly just proximal to the cubital tunnel (Neary et al., 1975). Pathological changes included the increased frequency of Renaut bodies and connective tissue at the level of the entrapment. There were also distortions of the internodes that consisted of bulbus enlargements at the ends of internodes directed away from the level of the entrapment and at the opposite ends of the internodes, thinning and retraction of the myelin. In ulnar nerves associated with ulnar hand muscle wasting (Neary, Eames, 1975) comparable but more extensive internode changes, including internode demyelination at the level of injury, have been described. The bulbar swellings were evident as much as $5 \mathrm{~cm}$ proximal and $4 \mathrm{~cm}$ distal to the central part of the lesion.

The relation of the above structural abnormalities to the conduction changes in the median and ulnar nerves reported here is uncertain and likely to be dependent on more extensive quantitative investigations. The type and location of struc-

\section{REFERENCES}

BROWN W. F., and FEASBY, T. E. (1974). Estimates of Functional Motor Axon Loss in Diabetics. Journal of Neurological Sciences, 23, 275-293.

BUCHTHAL, F., and ROSENFALCK, A. (1971). Sensory Conduction from Digit to Palm and irom Palm to Wrist in the Carpal Tunnel Syndrome. Journal of Neurology, Neurosurgery and Psychiatry, 34, 243-252.

BUCHTHAL, F., ROSENFALCK, A., and TROJABORG, W. (1974). Electrophysiological Findings in Entrapment of the Median Nerve at Wrist and Elbow. Journal of Neurology, Neurosurgery and Psychiatry, 37, 340-360.

CHANG, K.S.F., LOW, W.D., CHAN, S.T., CHUANG, A. and POON, K.T. (1963). Enlargement of the ulnar nerve behind tho, medial epicondyle. Anat. Rec., $145,149-153$.

CHECKLES, N.S., RUSSAKOV, A. D., and PIERO, D. L. (1971). Ulnar Nerve Conduction Velocity - Effect of Elbow Position on Measurement. Archives of Physical Medicine and Rehabilitation, 52, 362-365.

CRAGG, B. G. and THOMAS, P. K. (1961). Changes in Conduction Velocity and Fibre Size Proximal to Peripheral Nerve Lesions. Journal of Physiology, 157, 315-327.

EISEN, A. (1974). Diagnosis of Ulnar Nerve Palsy; An Electrophysiologic Study. Neurology (Minneap) 34, 256-62.

EISEN, A., DANON, J. (1974). The Mild Cubital Tunnel Syndrome: Its Natural History and Indications for Surgical Intervention. Neurology (Minneap), 24, 608-613.

FEINDEL, W., and STRATFORD, J. (1957). The Role of the Cubital Tunnel in Tardy Ulnar Palsy. Canadian Journal of Surgery, 1, 287-300.

JENSEN, E. (1959). Ulnar Perineuritis. Acta. Psych. et Neurol., Scand., 34, 205-221.

MARIE, P. and FOIX, C. (1913). Atrophie isolée de l'éminence thénar d'origine 
neuritique, rôle du ligament annulaire antérieur du carpe dans la pathogénie de la lésion, Rev. Neurol., 21, (ii) 647.

McGOWAN, A. J. (1950). The results of Transposition of the Ulnar Nerve for Traumatic Ulnar Neuritis. Journal of Bone and Joint Surgery, 32-B 293.

NEARY, D., and EAMES, R. A. (1975). The Pathology of Ulnar Nerve Compression in Man. Neuropathology and Applied Neurobiology, 1, 69-88.

NEARY, D., OCHOA, J. and GILLIATT, R. W. (1975). Sub-clinical Entrapment Neuropathy in Man. Journal of the Neurological Sciences. 24, 283-298.

NICOLLE, F. V. and WOOLHOUSE, F. M. (1965). Nerve Compression Syndromes of the Upper Limb. The Journal of Trauma, 5, 313-318.

OCHOA, J., FOWLER T, J, and GILLIATT, R. W. (1972). Anatomical Changes in Peripheral Nerves Compressed by a Pneumatic Tourniquet. Journal of Anatomy (London), 113:3, 433-455.

OCHOA, J. and MAROTTE, L. (1973). The Nature of the Nerve Lesion Caused by Chronic Entrapment in the Guinea-pig. Journal of the Neurological Sciences, 19, 491-495.
PAINTAL, A. S. (1965). Effects of Temperature on Conduction in Single Vagal and Saphenous Myelinated nerve Fibers of the Cat. Journal of Physiology, 180, 20-49.

PAYAN, J. (1969). Electrophysiological Localization of Ulnar Nerve Lesions, Journal of Neurology, Neurosurgery and Psychiatry, 32, 208-220.

RASMINSKY, M. (1973). The Effects of Temperature of Conduction in Demyelinated Single Nerve Fibers. Archives of Neurology, 28, 287-292.

RICHARDS, R. L. (1945). Traumatic Ulnar Neuritis: The Results of Anterior Transposition of the Ulnar Nerve. Edinb. Medical Journal, 52, 14-23.

ROBBINS, H. (1963). Anatomical Study of the Median Nerve in the Carpal Tunnel and Etiologies of the Carpal Tunnel Syndrome. Journal of Bone and Joint Surgery, 45A, 953-966.

SIMPSON, J. A. (1956). Electrical Signs in the Diagnosis of Carpal Tunnel and Related Syndromes. Journal of Neurology, Neurosurgery, and Psychiatry, 19, 275-280.

SINGH, N. BEHSE, F. BUCHTHAL, F. (1974). Electrophysiological Study of Peroneal Palsy. Journal of Neurology, Neurosurgery and Psychiatry, 37, 1202-1213.
SUNDERLAND, S. and BRADLEY, K. C. (1952). The perineurium of Peripheral Nerves. Anat. Rec. 113:2, 125-141.

STAAL, A. (1970). The Entrapment Neuropathies. In Vinken, P. J., Bruyn, G. W. (Editors): Handbook of Clinical Neurology. Amsterdam and New York, North-Holland Publishing Company 285-325.

THOMAS, P. K. (1960). Motor Nerve Conduction in the Carpal Tunnel Syndrome. Neurology, 10, 1045-1050.

THOMAS, P. K. and FULLERTON, P. M. (1963). Nerve Fiber Size in the Carpal Tunnel Syndrome. Journal of Neurology. Neurosurgery and Psychiatry, 26, 520-527.

THOMAS, J. E., LAMBERT, E. H., and CSEUZ, K. A. (1967). Electrodiagnostic Aspects of the Carpal Tunnel Syndrome. Archives of Neurology, 16, 635-641.

WADSWORTH, T. G., and WILLIAMS, J. R. (1973). Cubital Tunnel External Compression Syndrome. British Medical Journal, 1, 662-666.

WIEDERHOLT, W. C. (1970). Median Nerve Conduction Velocity in Sensory Fibers Through Carpal Tunnel. Archives of Physical Medicine and Rehabilitation, (June, 1970), 328-330. 